\title{
Magia, desposesión y poder soberano. Análisis de relaciones de género en torno a las almamulas y estudiantes de magia en Santiago del Estero, Argentina
}

\section{Lucas Gabriel Díaz Ledesma ${ }^{1}$}

${ }^{1}$ Universidad Nacional de La Plata, Argentina. Correo electrónico: lucasdiazledesma@gmail.com

\section{Resumen}

En este trabajo se realiza un análisis basado en narrativas en torno a las experiencias cotidianas de personas que viven en Santiago del Estero, Argentina, mediadas por un registro mítico, uno religioso y otro sexogenérico. Para ello se trabaja con dos figuras míticas, por un lado estudiantes de magia y por otro almamulas. En el primer caso se efectúa una descripción de dicho caso y su relación con la bruja, ambos clave para comprender la magia, las representaciones de la sexualidad y la moral y el pacto con lo diabólico. En el segundo caso, se retoma el análisis de las mujeres en situación de incesto (las almamulas) para entender la posesión de sus cuerpos por parte de los soberanos patriarcas, acto que implica la habilitación y jactancia de rasgos masculinos hegemónicos. Esta posición determina la expresividad de las prácticas dirigidas hacia los demás varones y a la comunidad en general.

Palabras clave: magia, almamulas, estudiantes, masculinidad hegemónica, género. 


\begin{abstract}
In this article, I make an analysis based on narratives about everyday experiences of individuals living in Santiago de Estero, Argentina, mediated by a legendary record; one religious and other sex-generic. In order to do this, work with two mythical figures, firstly students of magic and on the other hand, almamulas. In the first case, I carry out a description of the case and its relationship with the witch, both are essential to understand magic, the representations of sexuality and morality and the pact with the devil. In the second case, I take up the analysis in lathe to women in situation of incest (the almamulas) to understand the possession of their bodies by the sovereign patriarchs, act which involves empowerment and boasting of hegemonic masculine traits. This position determines the expressiveness of practices directed toward other males and the community in general.
\end{abstract}

Keywords: magic, almamulas, students, hegemonic masculinity, gender.

RECEPCiÓN: 30 DE ENERO DE 2016 / ACEPTACIÓN: 7 DE JULIO DE 2016

\title{
Aclaraciones iniciales
}

Este trabajo es resultado de la investigación en proceso que realizamos en el marco de la beca de investigación otorgada por el Consejo Nacional de Investigaciones Científicas y Técnicas (CONICET) de la República Argentina. ${ }^{2} \mathrm{El} \quad \begin{aligned} & { }^{2} \text { Esta investigación en procesoes la con- } \\ & \text { tinuación de la tesis de gradoen comu- }\end{aligned}$ 
nicación de la Facultad de Periodismo y Comunicación Social de la Universidad Nacional de La Plata Argentina, donde ya habíamos realizado un trabajo de campo de dos años aproximadamente en torno a ciertos ejes de la temática que acá presentamos. Eso significó el puntapié inicial en lo que concierne a la viabilidad de los planteos teórico-metodológicos. territorio está conformado por comunidades de la provincia de Santiago del Estero (del mismo país). El criterio de selección de los lugares está dado por la vigencia que ciertas narrativas míticas adquieren en la cosmología comunitaria, cuya circulación además de presentarse en la oralidad de los relatos, cobran preponderancia en retóricas de los medios masivos de comunicación, que se hacen eco de estos sucesos "sobrenaturales" que irrumpen en la cotidianidad y los toman como factores de construcción de sucesos noticiables.

El objetivo es comprender las tramas de sentido en torno a la "cotidianidad" - escenario donde transcurren las dinámicas de relacionamiento con los demás, con la naturaleza, el monte, la representación sobre la vida, la muerte, la curación, el espacio lúdico- que se urden en los relatos de experiencias de varones y mujeres. Se parte de entender que operan de manera compleja una dimensión mítico-cosmológica, una de género [s] y sexualidad/es, y otra de religiosidad.

Dimensión mítica se refiere a una realidad compleja que reactiva un pasado primigenio - $\mathrm{a}$ partir de pervivir tradiciones, normas, modos de ser y vivir - de constitución colectiva en las retóricas actuales, manteniendo vivas las significaciones (Elíade, 2005) ritos y acciones en la vida comunitaria.

Los relatos también remiten a prácticas donde las relaciones de género son clave, dado que las tramas de la sexualidad y el parentesco se organizan en cosmologías patriarcales de dominación del 
universo femenino, que se remontan en la colonial modernidad (Segato, 2010) resguardo del honor y la conformación de masculinidades hegemónicas (como se verá prontamente en el texto) y que inclusive sus significaciones y puesta en práctica se articulan en una relación con la dimensión mítica.

Esto es porque en Santiago del Estero la figura de "la almamula" es nodal en las relaciones de género, en el delineamiento de la moral, en la sexualidad, en las prácticas de "incesto" ${ }^{3}$, en la concepción del placer y en la circulación del poder. Aquí es preciso un paréntesis para explicar en qué consiste el mito de "la almamula" utilizando los relatos de informantes. Es un ser mitológico: se trata de una persona que se convierte

${ }^{3}$ Se entrecomilla esta palabra porque los informantes jamás la utilizan y si se clasifica el ejercicio de su sexualidad a partir de un término que a veces interpela modos adecuados y no adecuados de tramitación de la misma, se estaría ejerciendo una violencia logocéntrica. Por lo pronto se usa a modo de ensayo. en animal. Tiene ojos rojos, escupe fuego por la boca, emite alaridos ensordecedores y además tiene cadenas. Sale los días de cambio climático y de noche. Su objetivo es comer animales domésticos por dentro. Otros testimonios dicen que busca los corazones de niños que no hayan sido bautizados bajo alguna denominación de la religión cristiana. Este animal mítico y temerario es una mujer que sufre el castigo de la transfiguración y pérdida de su yo social por haber cometido incesto con su padre, hermano o hijo (o tío o abuelo). La almamula no es una sola, sino que hay tantas como relaciones "incestuosas" ocurran. Es decir, toda mujer es potencialmente almamula en tanto sexuada para las relaciones de género comunitarias (Díaz Ledesma, 2012). 
Estas experiencias también se comprenden en diálogo con el campo la religiosidad popular, al poder entenderlas como yuxtaposiciones de repertorios diferentes en la relación con lo sagrado, y entre cosmologías nativas y las coloniales que configuran los procesos de mestizaje y las temporalidades que interactúan.

Por todo esto, interesa conocer las tramas de sentido que configuran los relatos de experiencias cotidianas, donde articulan estas dimensiones, delimitando las prácticas cotidianas en tramas performativas, es decir en puestas en acto. Así reconocer bajo qué condiciones históricas concretas, materiales y simbólicas de producción se entretejen estas gramáticas que permiten configurar procesos identitarios en lo actual en Santiago del Estero.

\section{Pistas metodológicas y encuadres conceptuales}

Este trabajo se enmarca en una perspectiva etnográfica, que "como enfoque la etnografía es una concepción y práctica de conocimiento que busca comprender los fenómenos sociales desde la perspectiva de sus miembros (entendidos como 'actores', 'agentes' o 'sujetos sociales')" (Guber, 2001: 111-112).

Quien se dedica a la investigación social es difícil que comprenda una acción determinada sin entender los parámetros, las simbolizaciones y los marcos de producción de sentido sin tener en cuenta las caracterizaciones de sus propios/as protagonistas. Se trata de elaborar una construcción entre lo que dicen "los/as nativos/ 
as" ${ }^{4}$ junto con la formulación teórica del/a investigador/a.

Respecto de las técnicas de recopilación de información con las que se intenta llegar al campo, se puso en práctica la observación como herramienta fundamental, pues permitió entender los procesos simbólicos de las prácticas sociales, más allá de los límites de lo dicho en la expresión oral, como las dimensiones significantes que operan en sus miradas, en sus juegos de interrelación corporal, las marcas en los cuerpos; huellas y marcas de sentido densas y comunicativas.

Por ejemplo, cuando se realizan entrevistas grupales y participan de ellas varones y mujeres guiados/as por algún tópico de discusión, estas últimas generalmente buscan con su mirada algún tipo de aprobación por parte de ese varón que se encuentra allí para enunciar lo que quiere decir. Por ello resulta clave observar las dinámicas de sus cuerpos, sus posiciones corporales, los modos de circulación del micro poder más allá de lo que puedan decir verbalmente.

Otra técnica central es la entrevista, que consiste en la conversación entre dos personas como mínimo, que dialogan sobre ciertos esquemas o pautas acerca de un problema o cuestión determinada. La entrevista puede tener diversas formas, pero cada vez que se llega al campo resulta dificultoso realizar una entrevista en profundidad o no directiva o "en estado puro", pues por las dinámicas interactivas que se presentan comienza a operar una relación con 
el/a entrevistado/a que implícitamente requiere de acciones de improvisación.

Sin embargo, quizás el término que más se adecue es el de "charlas" muchas veces condicionadas por los tópicos que los/as mismos/ as informantes establecen, desean hablar o desarrollar. En este encuentro con los/as otros/as claramente ellos/as determinan cómo, cuándo, dónde, de qué hablar y con quién los/as interpela.

Una primera investigación realizada entre los años 2008 y 2010 en el marco de la Licenciatura en Comunicación Social (Universidad Nacional de La Plata, Argentina), se llevaron a cabo observaciones participantes, grupos de discusión y entrevistas dirigidas, organizadas en función de disparadores que dependían de las diversas situaciones de encuentro investigativo que se iban generando (pero también de los tópicos que se buscaba indagar en relación a los mitos y las relaciones de género).

Luego se regresó a alguno de estos lugares de manera esporádica para seguir teniendo vínculo con informantes, hasta que se volvió formalmente para el trabajo de campo en julio del 2014 hasta la actualidad, ampliando la perspectiva de investigación tal como se enunció en páginas anteriores.

Se llevan realizadas 15 entrevistas a varones y mujeres que viven en localidades rurales y urbanas de Santiago del Estero. En dichas charlas a veces participan más de una persona, y se buscó jóvenes, varones, mujeres, adultos/as y adultos/as mayores para trabajar la perdurabilidad de la dimensión mítico-religiosa de los relatos, y atender así la mayor complejidad de sus narrativas posible. 
En este artículo se retoman sus testimonios para conformar un análisis, pero cabe remarcar que sus identidades fueron cambiadas a fin de resguardarlas.

En su mayoría son personas que no han culminado sus estudios primarios o secundarios. Todos/as son padres o madres, a excepción de algunos/as jóvenes de entre 15 y 17 años.

Las mujeres de zonas urbanas manifestaron abiertamente sufrir algún tipo de violencia de género, de una modalidad o económica, o psicológica o física. Incluso remarcaron que alguna mujer cercana a su vínculo la padecía. En estos contextos deben comprenderse las narrativas en torno a las almamulas, estudiantes y brujas que son los síntomas mágico-religiosos de la cultura para comprender la hechicería y la tramitación sexual en tanto entramados subrepticios.

\section{La comunicación/cultura y los feminismos poscoloniales}

Esta investigación parte y se inscribe del campo de los estudios de la Comunicación Social en tanto terreno epistemológico trandisciplinar.

La comunicación como campo de saber académico no puede pensarse separada de lo social y lo cultural. "Al no estar integrado por una disciplina sino por un conjunto de saberes y prácticas pertenecientes a diversas disciplinas y campos, el estudio de la comunicación presenta dispersión y amalgama" (Martín Barbero, 1990: 3). 
La riqueza de los estudios en comunicación consiste en desdibujar las fronteras disciplinares para aprovechar las potencialidades de la multiplicidad e indisciplinar los campos, puesto que son espacios de poder en la medida que solidifican estatutos de verdad nomenclativos de lo real. Por lo tanto este trabajo coincide en tomar la postura de construir un campo amplio, transdisciplinar, que asuma lo político del contexto en el que se crea. Ello implica pensar a la transdisciplina como un conjunto de rearticulaciones de estrategias conceptuales que habilita la producción de objetos de estudio específicos (Elizalde, 2007).

Es más:

La comunicación no es todo, pero debe ser hablada desde todas partes; debe dejar de ser un objeto constituido, para ser un objetivo a lograr. Desde la cultura, desde ese mundo de símbolos que los seres humanos elaboran con sus actos materiales y espirituales, la comunicación tendrá sentido transferible a la vida cotidiana (Schmucler, 1984: 8).

Conceptualizar la comunicación y la cultura como un término barrado invita a pensarlos como campos complementarios, inseparables entre sí.

La cotidianidad se tornó un tema de especial interés para la comunicación y los estudios de cultura popular que abonan el debate comunicación/cultura. La cotidianidad —espacio de producción de la cultura- es ese escenario de creación y apropiación de 
los sectores populares, territorio donde se promueve la lucha por el sentido. Se pretende hacer un análisis de lo popular en el campo de la comunicación anclado en los conflictos que articula la cultura (Martín Barbero, 1987) y habilita direccionar respecto del tejido material y simbólico de la cotidianidad. La cotidianidad es también el escenario donde circula la posibilidad performática de la transformación, una cotidianidad opaca, oblicua, en tanto escena de yuxtaposición de temporalidades.

Por otro lado, los feminismos poscoloniales buscan la construcción de conocimiento situado para la producción de una Epistemología Feminista Latinoamericana, "que parta desde los márgenes de vida de las 'Otras' del feminismo hegemónico: indígenas y campesinas, afrodescendientes, diaspóricas y migrantes, lesbianas, trabajadoras en las maquilas, trabajadoras del sexo, trans" (Bidaseca y Vázquez Laba, 2011: 7), puesto que es ineludible poner en jaque los órdenes y las condiciones históricas de dominación que ubican a las mujeres y a los sujetos feminizados en posición de subalternidad y violencia estructural.

Esto conlleva:

descolonizar el conocimiento y develar la manera en que las representaciones textuales de aquellos sujetos sociales — construidos como "los otros" en distintos contextos geográficos e históricos- se convierten en una forma de colonialismo discursivo que no sólo da cuenta de una realidad, sino que la construye (Suárez Navaz y Hernández, 2008: 10). 
Se parte de pensar al racismo y a la colonialidad como constitutivas de las relaciones de género, distinto al posicionamiento del feminismo contemporáneo que entiende que la raíz de todos los problemas es el patriarcado y que la erradicación de la opresión sexista terminaría con las demás formas de dominación (Segato, 2010), y en rigor de verdad "hablar del patriarcado y no del racismo permite que las feministas blancas sigan actuando como explotadoras y opresoras. Sexismo, racismo, y explotación de clase constituyen interrelacionados de dominación" (Bidaseca y Vázquez Laba, 2011: 363).

Se trata de tomar al

género como objeto de análisis y así construir un pensamiento que parta del borde entre la episteme occidental y las epistemes de los pueblos colonizados, e instale a América Latina y los llamados países del Tercer Mundo como lugares legítimos de enunciación no pretendidamente universales (Bidaseca y Vázquez Laba, 2011: 363).

Así es que el género "se intersecta con modalidades raciales, de clase, étnicas, sexuales, regionales de identidades discursivamente constituidas" (Bidaseca y Vázquez Laba, 2011: 237).

En este sentido, los feminismos de color dejaron en claro que para comprender las tramas de las violencias en la cotidianidad, se deben recurrir a los enclaves interseccionales, comprendidos por clase, raza, género y sexualidades (Lugones, 2014). 


\section{Análisis}

\section{Estudiantes de magia y brujas: pactos,} magia, curación y género

Estudiantes

La socióloga argentina Hebe Vessuri (1970) y el antropólogo argentino José Luís Grosso (2008), denominan a los estudiantes de magia como formaciones simbólicas y comunitarias que estudian con el diablo o zupay (término quichua $\left.{ }^{5}\right), \quad \begin{aligned} & { }^{5} \text { Idiomanativo de Santiago del Estero } \\ & \text { con ráces quechuas. }\end{aligned}$ aprendiendo saberes oscuros y de antaño con los cuales inciden en el destino de cualquier persona de la comunidad.

Son personas que estudian para eso, para hacerle daño a la gente. Allá vivía un hombre, 'Papilo', que decían que él estudiaba, que él tenía muchos libros y velas cuando vos pasabas por la casa. Y contaban que cuando venían 'machaos' ${ }^{\prime 6}$ que se ${ }^{6}$ Ebrios. cruzaba un cajón de muerto. Y cuando han disparado a buscar gente, dice que ya no estaban (...) es un estudiante que se convierte en cosas (José Araujo. Entrevista Grupal № 2. Julio 2014).

Estudiar implica una aptitud vinculada a la lecto-escritura; como narraba Rosa Domínguez [en una charla informal en el año 2014] de la ciudad de La Banda (Santiago del Estero), ese libro de magia se lee además a la noche, jamás a la luz del día porque su conteni- 
do sólo es visible en la penumbra. Esto se puede vincular con lo que el antropólogo Michael Taussig explica en relación al poder de la magia de palabra impresa "dado que la ha adquirido ese poder durante el ejercicio de la dominación colonial (...) como en la Biblia y el derecho" (Taussig, 2012: 316), sobre todo si se considera la baja alfabetización en los sectores populares en Santiago del Estero. Pero además, la posibilidad metamórfica o transfigurativa es un rasgo clave de los/as estudiantes, pues pueden convertirse en cualquier tipo de animal o persona.

Por otro lado, los sentidos en torno a estas figuras se relacionan con prácticas curativas. Una entrevistada contaba que un "curandero" la había sanado y agregaba:

Los estudiantes aprenden para curar, pero siempre hacen pacto con el diablo. Algunos estudian para las dos cosas te voy a decir (Amanda Castro. Entrevista personal № 1. Enero 2015).

El rol comunitario consiste en curar una enfermedad o en provocarla mediante artes diabólicas de la salamanca. En este lugar se estudia de noche, en la oscuridad, en la ausencia de la luz. Son cuevas subterráneas e invisibles y es el espacio donde se aprenden las artes oscuras o se pide algún don o destreza que los/as ayude a destacarse. Los/as aspirantes deben ingresar desnudos/as y realizar una afrenta a representantes celestes de la fe cristiana (Grosso, 2008). Estas son las características que tienen en relatos de infor- 
mantes las salamancas, que hay tantas como posibilidades de intelección existen.

Incluso se lo relaciona con aquellas prácticas curativas que no tienen una explicación científica o que cuadre en el marco de las definiciones de los discursos de la modernidad iluminista.

Se destaca que aparece la mención del "pacto" como acción que marca un antes y un después en la práctica hechiceril, pues ese acto tiene un precio y el diablo jamás pierde, sino el pactante, que generalmente es hombre, pues es un asunto constitutivo de las masculinidades (Isla, 2004) y de relaciones de género patriarcales.

— ¿Dos caras del mismo fenómeno mágico? La posición de la bruja

Los atributos de las brujas, que también podría ser la curandera, oscilan entre la omnipotencia y el origen diabólico, pero ese poder también requiere de una combinación de un saber aprendido. "Tal aprendizaje combina, por un lado componentes sobrenaturales (...) que aseguran su adquisición inmediata en la diabólica salamanca, y por otro, la experimentación humana, que exige paciencia y tiempo" (Farberman, 2010: 105).

La historiadora además explica:

La bruja prueba su arte - a menudo con sus propios parientes-, lo enseña a otras candidatas y accede, merced a su caudal de conocimiento, a una jerarquía de especialista no siempre solidaria entre sí. En otras palabras, no todas las brujas llegan 
a ser 'finas', por mucho que concurrieran a las Salamancas y gozaran del favor y protección del Zupay (Farberman, 2010: 105).

En el barrio Río Dulce de la ciudad de La Banda, una informante contaba su experiencia sobre la concurrencia con una curandera:

Yo he andado en una de esas hace mucho porque mi papi estaba enfermo. Me he ido para doña Machoca, que dicen que era una bruja de primera. Y ella me dice 'a tu papi le han hecho un mal. Traé tres gallinas negras y velas rojas (...) a tu papi no le van a cortar las piernas y él va a vivir muchos años más'. Y le pregunto para qué las gallinas, y me dice 'para que salga el mal tengo que sacrificar las gallinas. Con la sangre de las gallinas se va a ir. Y yo tengo que ir un viernes a un lugar donde esté sola, y sacrificando la gallina, nosotros aumentamos la visión, y nosotros necesitamos 100 ojos para estar', porque dice que cuando ellos se ponen en el piso, los otros males andan, muchas cosas andan y tiene que tener muchos ojos para que ninguno le llegue a ella. Y esos son los ojos de los animales. iYo le tenía un miedo! porque si vos entrabas a la casa de ella era todo santos, raros. Ella era bruja y quería que yo siga yendo a la casa (Nancy Argañarás. Entrevista personal № 5. Julio 2014). 
Es decir, el padre de Nancy encontraría en doña Machoca la posibilidad de sanarse más allá de los diagnósticos y pronósticos de la medicina tradicional.

Sacrificio de animales, hierbas medicinales y velas, son el repertorio de elementos que estas mujeres utilizan en su arte mágico o curativo (continuidad ancestral e histórica). Hay un continuum entre brujas y curanderas que van desde las curaciones basadas en conocimientos de hierbas y plantas hasta procedimientos mágicos ancestrales. Aquí la magia son creencias, prácticas y conocimientos que inciden en la naturaleza y en las personas (Vessuri, 1970) y conocimientos y palabras que permiten crear cosas (Taussig, 2012).

Por otro lado, informantes arguyen que ciertas mujeres curanderas son consideradas "brujas", o más "finas" [término que aparecía en el vocabulario de los juicios a hechiceras llevados a cabo en 1700 en Santiago del Estero (Farberman 2005) y que aún continúa en la terminología de los/as informantes]. Ellas son peores que los hombres porque hacen trabajos "más fieros", de más peligrosidad. Como en la cita de Farberman, estos saberes se practican en parientes, tal como lo menciona la siguiente informante:

A cuatro kilómetros de aquí, ${ }^{7}$ en MachaJuay, víbora brava quiere decir. Mi mamá tenía ${ }^{7}$ De Jumial Grande, a 400 kilómetros de la ciudad capital de Santiago del una amiga, y la señora esa había estudiado Estero. para ser bruja, y el demonio te pide que estudies en tu hija o en tu hijo, al que más lo mezquinas, entonces esta señora había estudiado en la hija, para poder ser más "fina" y el diablo le ha 
pedido a ella que entregue a su hija. Y la madre ha sido más fina para hacer daño a otra persona (Amalia Cáseres. Entrevista personal № 1. Enero 2015).

Por ello, se reconoce que la dimensión sexo-genérica es constitutiva al momento de tramar la posición representativa de las curanderas o brujas dado que adquieren un plus de "malignidad" por su "peligrosa feminidad". En la reconstitución cartográfica de estas mujeres, casi siempre son solteras, viudas o con una gran presencia en la comunidad, con una personalidad que se destaca y que incluso viven su sexualidad no necesariamente constreñida al sexismo o la heterónoma.

¿Es posible que sean más peligrosas porque sus saberes de antaño en cierto modo ponen en jaque el orden establecido? "el agente del daño era habitualmente la vecina, la falsa amiga, la tierna amante" (Farberman, 2010: 103) incluso la médica podría encarnar la personificación de una bruja, esto en pleno siglo XX (Farberman, 2010) y en la actualidad. Tales rasgos siguen presentes cientos de años después y muestra no sólo la incomodidad de estas mujeres a constreñirse a mandatos patriarcales, sino también la necesidad de revelarse contra ellos.

Esto podría articularse con los aportes de diferentes trabajos feministas (sobre todo de la antropología del género como Verena Stolcke (2004), Sherry Ortner (1979), Michelle Rosaldo (1979) entre otras) que sostienen que la sociedad adjudica a la sexualidad de las mujeres no normadas por el orden del género, una idea 
cuya simbolización se la relaciona con la anomalía, la perversión, la peligrosidad, justamente por estar más próximas a la naturaleza y su contra partida, el universo masculino al universo cultural. Por ello la capacidad de transformar la naturaleza es un signo de intervención cultural que se asocia con superioridad y prestigio. Según axiomas occidentales, todo aquello que se vincule con la naturaleza y no pueda ser modificado o controlado por la cultura, es peligroso y requiere de domesticación y control.

Por otro lado, la masculinización femenina es el rasgo que le permite aparecer en la escena comunitaria como una particularidad excéntrica a destacar, puesto que como lo mencionan informantes, el coraje es una facultad del mundo de los varones y toda aquella mujer que se jacte de la búsqueda de un estatus igualitario, debe mostrar su posesión a modo de un pasaje ritual en público ante las afrentas de lo desconocido e incluso en el ejercicio de la magia.

Cuando la bruja realiza el pacto con el diablo, aprende la malignidad, las artes oscuras, encarna en las representaciones occidentalizadas en torno a su figura, la amenaza y la puesta en jaque de los mitos modernos bajo los cuales se constituye la opresión femenina: el mito del amor romántico, el mito de la pasividad erótica, y el mito de la mujer madre (Fernández 2014). Por lo tanto, serían ejes para seguir profundizando en el campo, pues se comprende que las representaciones respecto de la peligrosidad femenina son resabios, remanentes, cristalizaciones de sentido que se remontan a la colonial modernidad (Segato, 2010) y que operan en la actualidad. 


\section{Las almamulas: desposesión y poder soberano}

Todos los sentidos que dan forma a las almamulas cargan con un fuerte significante estigmatizante y performativo. Por un lado tiene que ver con la función performativa de las narrativas míticas, en la medida en que no sólo establecen regímenes de verosimilitud respecto a lo que puede acontecer o no en el registro de lo cotidiano, sino que además siempre el mito interpela a prácticas que no necesariamente se explicitan en su contenido cultural manifiesto. A nivel comunitario se trata no sólo de cuidar que las almamulas no coman los corazones de algún/a bebé que no haya sido bautizada/o, sino de efectuar el ritual del bautismo como pasaje ritual necesario en el resguardo de las personas.

Siempre se condensa una función latente en el entramado simbólico del mito. Hablar de las almamulas no se remite únicamente a la presencia de un "bicho mítico" que siembra castigo y terror en un barrio, sino aludir directamente al "modo anómalo" — a ojos comunitarios - de tramitación de la sexualidad y a la necesidad de lavaje culpógeno mediante el sacrificio de la mujer-mártir.

Por otro lado, en lo que concierne al ejercicio deteriorante de las identidades, es decir el estigma, no se trata de un sujeto social desigual sino de la significación de un ente cratofánico — deidad que genera veneración y odio- receptáculo de la misoginia comunitaria y portador del terror que remarca la necesidad de prohibir, pues si una práctica es tan proscripta —en este caso el "incesto"-, es porque resulta factible de ser acontecida. Como se trató en otros artículos 
(Díaz Ledesma, 2015) el ejercicio del estigma representa el debate y la pregunta por la identidad porque a partir de allí se configuran las gramáticas mediante las cuales las mujeres ocupan un lugar de descrédito en el escenario comunitario, porque las significaciones míticas representan el repertorio de identificaciones que esos "yo" deben asumir. ${ }^{8}$

Y es así como opera la desposesión de los cuerpos, instalándose en la imaginería colectiva a partir de la solidificación de la narrativa mítica y posteriormente en el círculo íntimo de la cotidia-

${ }^{8}$ Dicho de otro modo, el estigma constituye un elemento que instaura el mecanismo dimórfico y binarizante de la configuración de las identidades: por un lado mujeres objetos, reificaciones de uso y abuso por parte de los varones y por otro, hombres despóticos, patriarcas que determinan el destino sexual de esas mujeres. nidad, pues se arraiga en el axioma que las corporalidades no les pertenecen a las mujeres sino por extensión de propiedad, son de sus varones. Desposesión en tanto quita de posibilidad del ejercicio de la autonomía respecto a las acciones, al deseo y a la voluntad y al propio cuerpo. Es decir, "el cuerpo es una inscripción narrativa, histórica, que soporta todos los modos institucionalizados de control" (Femenías, 2008: 8).

Ahora bien, son necesarias nuevas categorías sobre género en diálogo al conocimiento situado, articulado e interseccional que se aludía en páginas anteriores, por ello se comprende al género como "una construcción social y cultural que se articula a partir de definiciones normativas de lo masculino y de lo femenino, que crean identidades subjetivas y relaciones de poder tanto entre hombres y mujeres como en la sociedad en su conjunto" (Narotzky, 1995: 45). Además, es un constructo histórico que define y da sentido a la sexualidad, y que conforma un entramado de poder que opera por 
medio de ordenamientos complejos a través de normas, tradiciones, prácticas, valores, estereotipos, signos que se producen y reproducen en los discursos públicos que circulan en las instituciones sociales y que habilitan, limitan y/o restringen las prácticas de lo público y lo privado (Cremona, 2011).

Pero también se intersecta con otros vectores y modalidades como las raciales, étnicas, clasistas, sexuales, regionales y otras adscripciones identitarias para comprender la complejidad de las relaciones de opresión situadas.

\section{- La ley: el soberano patriarca}

En la escena donde el cuerpo femenino desposeído le pertenece al varón hegemónico, aparece la figura de un padre o hermano mayor (tíos o abuelos) que se arroga el derecho de tomar como propio el cuerpo de una hija o hermana menor, aún a sabiendas del carácter punitivo de esa práctica, pero dejando como marca simbólica que no hay más ley que ellos o por encima de ellos.

Yo conozco una chica, me contaba que el hermano la obligaba a tener relaciones y la había amenazado (...) después la han mandado a Buenos Aires a ella. Había sido que el chango le decía que si ella hablaba ella la iba a pasar mal, y ella le tenía miedo (Celina Argañarás. Entrevista grupal № 3. Julio 2010).

Este muchacho, que ha sido mi sobrino (...) nosotros sabemos positivamente de que él se ha separado de mi sobrina, 
que ha sido la mujer de él, porque la mortificaba, la hacía cualquier cosa, y dentro de eso, él vivía con su hija inatural!, que hoy en día, está compartiendo la vida con ella (...) ha presentado a su propia hija como mujer propia (...) y hoy, él tiene un bebé de su propia hija, que es un bebé discapacitado, y vive en una silla de ruedas. Incluso él mismo ha dicho yo me llamo César José Rojas, el almamula (...) Realmente él la ha obligado (...) si ella llegaría a irse con otro hombre, la va a matar, así que lo está pasando re mal, porque él es agresivo y sé que la va a matar (Bernardo Araujo. Entrevista personal № 2. Julio 2010).

Como lo señala Rita Segato en torno a los crímenes de género perpetrados en la intimidad del espacio privado "si a abrigo del espacio doméstico el hombre abusa de las mujeres que se encuentran bajo su dependencia — hijas, hijastras, sobrinas, esposas, etc.- - es porque puede hacerlo, es decir, porque éstas ya forman parte del territorio que controla" (Segato, 2006: 28). Incluso a partir de las prácticas de desposesión —incesto-, hay un interés por parte de los varones de comunicar el domino sexual de sus mujeres, dejando huellas en sus cuerpos (embarazos, cicatrices, golpes, modos de comportamiento de las víctimas que permiten leer la subyugación, etc.). Pero además es un modo de inscribirse en la gramática comunitaria, exhibiendo a sus pares varones la capacidad de dominio sobre sus mujeres, como acto visibilizador y dimensión expresiva y comunicativa de sus rasgos identitarios de soberano y de masculi- 
nidad hegemónica, caracterizada por despotismo, misoginia, provisión sexual, otorgadora del reconocimiento y respeto comunitario.

No puede negarse la exhibición de poder que se establece en el control y regulación de la vida y la sexualidad de las propias mujeres, comunicando que por fuera de las reglas que el soberano patriarca ejerza, no hay ley. O en otras palabras, él determina la ley, su ley, que reside en un poder sobre la dominación física y moral del otro: "no existe poder soberano que sea solamente físico. Sin la subordinación psicológica y moral del otro lo único que existe es poder de muerte, y el poder de muerte, por sí solo, no es soberanía" (Segato, 2006: 19).

Entonces icómo se explican estos mecanismos comunitarios de inteligibilidad que consisten en concebir a las prácticas de incesto como uno de los vejámenes más aberrantes? y a la vez icómo es posible que un hombre que demuestra a los demás varones que es capaz de ejercer el dominio de todas sus mujeres adquiera el reconocimiento comunitario? No se afirma que sean concebidos como modelos ejemplificadores a emular, pero sí que son respetados en el espacio colectivo en tanto nadie por fuera del círculo íntimo se animaría a interferir en las dinámicas vinculares de su familia, o a ejercer una denuncia a las fuerzas del Estado.

Quizás la respuesta resida en que el proceso regulador de la práctica prohibida consumada requiera de una víctima sacrificial donde depositar la culpa y el repudio moral colectivo y de un victimario responsable del acto. Paradójicamente, ambos roles se con- 
densan en la mujer almamula, pues en ella se recae la revulsión comunitaria que genera un tabú.

Rita Segato explica, en relación a los feminicidios ocurridos en Ciudad Juárez, que cuando hay una disonancia entre lo que se espera que suceda en la vida y lo que ocurre en realidad, como mecanismo cognitivo defensivo se genera en la colectividad un odio difícil de asimilar hacia la víctima que encarna este suceso. En palabras de Segato:

La comunidad se suma más y más en una espiral de misoginia que, a falta de un soporte más adecuado para deshacerse de su malestar, le permite depositar en la propia víctima la culpa por la crueldad con que fue tratada. Fácilmente optamos por reducir nuestro sufrimiento frente a la injusticia intolerable testimoniada, aduciendo que 'debe haber una razón' (Segato, 2006: 34).

Este es el mismo mecanismo que opera en las mujeres almamulas, que cargan el ultraje del tabú del incesto y la responsabilidad del quebrantamiento de la ley de exogamia comunitaria. Como punto de fuga de la ininteligibilidad de los sucesos y como recipiente del malestar que genera una práctica antimoral que acontecen en el barrio, las almamulas viven el desprecio, el estigma y la misoginia de su comunidad al punto de perder su humanidad y su derecho a la dignidad.

Pero no debe dejarse de remarcar que los miembros de su colectividad deciden asumir una postura de miopía social y negar el 
impacto que tienen los mandatos imperativos de la masculinidad hegemónica, cuyas gramáticas se configuran a partir de patrones como la agresividad, la heterosexualidad obligatoria, la subyugación de los miembros de sus familias, la imposibilidad de mostrar rasgos sensibles, la competencia exacerbada entre pares, provisión material e incontinencia sexual (Connel, 1997; Vásquez del Águila, 2000) pero que además, su puesta en acto requiere del pago de la vida moral de los cuerpos femeninos, pues se ven supeditados a los mandatos soberanos del patriarca, quien determina cómo viven o deben vivir sus mujeres.

\section{(In) conclusiones}

La figura del estudiante o curandero/a tiene una especial conexión con lo sagrado y el ejercicio de las artes oscuras y curativas. El estudiante aprende la magia con el diablo y adquiere saberes que influyen necesariamente en la vida de los/as demás, para hacer daño (provocando muertes catastróficas) o hacer el bien, mediante prácticas curativas, al igual que la bruja.

Sobre ellas: puede decirse que aparecen significaciones que se asemejan a las del estudiante, pero con la particularidad de destacar de uno u otro modo, una peligrosidad mayor que se relaciona con su posición sexo-genérica en la comunidad y una construcción generizada en clave histórica. Las brujas son más peligrosas que los estudiantes porque las mujeres son más pícaras, fuertes o malas que los varones. Son mujeres independientes, con una gran perso- 
nalidad, sexuales, que ponen en jaque los marcos moralizantes de las comunidades. Por ello, la preeminencia colonial no sólo se expresa en las residualidades culturales, o en la rememoranza de la cosmología mítica, sino además en los marcos moralizantes que constituyen las relaciones de género. Esta imaginería opera directamente en el ejercicio de la magia y dimensión sexo-genérica de las prácticas.

La puesta en acto del estigma en las almamulas representa el debate y la pregunta por la identidad porque a partir de allí se configuran las gramáticas mediante las cuales las mujeres ocupan un lugar de descrédito y misoginia en el escenario comunitario, porque las significaciones míticas representan el repertorio de identificaciones que esos "yo" deben asumir —en posición de subordinación-y porque en la dinámica relacional, los varones entienden que para ocupar prestigio en la comunidad deben encarnar el rol de masculinidad despótica, de subyugación, de dominio y control de las mujeres de su círculo íntimo. Es decir, masculinidades soberanas, que establecen cómo debe tramitarse la sexualidad o no en el marco de su ley a partir de la desposesión de los cuerpos femeninos. Tratar de tener una lectura aguda respecto de la escucha sobre las tramas expresivas hacia los interlocutores de los actos de desposesión de los cuerpos: qué urdimbres enunciativas se aglutinan en las prácticas de género de estos soberanos patriarcas. Además, cabe la pregunta por el rol que ocupa la comunidad en tanto escenario de producción de esta trama, donde las prácticas adquieren una dimensión significante y expresiva en los marcos de inteligibilidad de la misma. 
No basta con una descripción densa de lo que sucede en la superficie de la cultura y la cotidianidad, sino de pensar estos procesos, estas matrices de género y sexualidades (religiosas y míticas) en diálogo tiesto con la historicidad de los territorios del norte argentino, con los mestizajes, la subyugación y subordinación que sufrieron los pueblos latinoamericanos en la historia de la colonización y en sus matrices miméticas.

Se adscribe a la vigilancia de las epistemes y se previene la guetificación de las temáticas que disciplinan la discusión. Se cree que el camino está en partir desde una perspectiva crítica en relación a temáticas, miradas, objetos, metodología y posicionamientos político-epistemológicos, apelando a la transversalidad, a los cruces y a la vigilancia de las condiciones de producción de las preguntas y de objetos y al diálogo entre conocimiento académico y el conocimiento cívico.

Se busca pensar, discutir y problematizar colectivamente, de manera conjunta e imprescindible con los/as colaboradores/as de la investigación, para generar desde allí premisas que habiliten concebir modos de vivir, existir y habitar en espacios de apuesta por la emancipación.

\section{Bibliografía}

Bidaseca, Karina y Vázquez laba Vanesa (2011). Feminismos y poscolonialidad. Descolonizando el feminismo desde y en América Latina. Buenos Aires: Ediciones Godot. 
Cremona, Florencia (2011). Seminario de Comunicación y Género. Cuaderno de cátedra. Buenos Aires: Ediciones de Periodismo y Comunicación EPC. Facultad de Periodismo y Comunicación Social, Universidad Nacional de La Plata.

CONNEL, Robert (1997). "La organización social de la masculinidad". En Teresa Valdés y José Olavaria (Eds): Masculinidades, Poder y Crisis. Chile: Isis Internacional, FLACSO.

DíAz Ledesma, Lucas Gabriel (2012). "El almamula y el duende. Discursos míticos aglutinantes de sentidos sociales que constituyen las relaciones de género en Santiago del Estero". UCSE, Santiago del Estero, Argentina. XVI Jornadas Nacionales de Investigadores en Comunicación.

(2015). "Rasgos identitarios estigmatizantes: las almamulas, el incesto y las relaciones de género opresivas en Santiago del Estero, Argentina”. En Fernando Palazzolo y Gabriel Morales (Eds): Identidades y diversidades estigmatizadas. Estudios sobre la construcción de los otros en sociedades multiculturales y desiguales. IEPC-Ediciones de Periodismo y Comunicación ISBN: 978-950-34-1214-5. IICom-Instituto de Investigaciones en Comunicación-Facultad de Periodismo y Comunicación Social, Universidad Nacional de La Plata.

De Andrés CASTEllanos, Soledad (2000). "Sexismo y lenguaje: El estado de la cuestión: reflejos en la prensa". Espéculo: Revista de Estudios Literarios, 16-26.

ELÍADE, Mircea (2005). Mito y realidad. Barcelona: Kairós. 
ElIZALDE, Silvia (2007). "De encuentros y desencuentros. Hacia un mapa indicial del vínculo género/comunicación". Cuadernos Críticos de Comunicación y Cultura, Vol 3, 15-40.

FARBERMAn, Judith (2005). Las salamancas de Lorenza. Magia, hechicería y curanderismo en el Tucumán Colonial. Buenos Aires: Siglo Veintiuno Editores.

- (2010). Magia, brujería y cultura popular. De la colonia al siglo xx. Buenos Aires: Sudamericana.

Femenías, María Luisa (2008). "De los Estudios de la Mujer a los debates sobre Género", Historias con mujeres, mujeres con historias. Teorías, historiografía y metodologías. Buenos Aires: UBA.

FERnÁndeZ, Ana María (2014). La mujer de la ilusión. Pactos y contratos entre hombres y mujeres. Buenos Aires: Paidós.

Grosso, José Luís (2008). Indios muertos, negros invisibles. Hegemonía, identidad y añoranza. Córdoba: Editorial Brujas y Encuentro Grupo Editor.

Guber, Rosana (2001). La etnografía. Método, campo y reflexividad. Colombia: Grupo Editorial Norma.

Isla, Alejandro (2004). "Canibalismo y sacrificio en las dulces tierras del azúcar", Estudios Atacameños. Arqueología y antropología surandinas Núm. 19, pp. 135-156.

LugOnes, María (2014). "Colonialidad y Género: hacia un feminismo descolonial”, en Walter Mignolo [et.al.] eds. Género y descolonialidad, pp 13-42. Buenos Aires: Ediciones del Signo.

Martín BARBero, Jesús (1987). Procesos de comunicación y matrices de cultura. Itinerario para salir de la razón dualista. México: FELAFACS GG. 
-(1990). Memoria narrativa e industria cultural. Colombia: Universidad del Valle.

NAROTZKY, Susana (1995). Mujer, mujeres y género. Una aproximación crítica al estudio de las mujeres en las Ciencias Sociales. Madrid: Consejo Superior de Investigaciones Científicas.

ORTNER, Sherry (1979). "iEs la mujer con respecto al hombre lo que la naturaleza con respecto a la cultura?", en Harris Olivia y Kate Young (comp.). Antropología y feminismo, pp 109-131. Barcelona: Anagrama.

Rosaldo, Michelle Zimbalist (1979). "Mujer, cultura y sociedad: Una visión teórica", en Harris Olivia y Kate Young (comp), pp 153-181. Antropología y feminismo. Barcelona: Anagrama.

SCHMUCLER, Héctor (1984). "Un proyecto de comunicación cultura”. En Revista Comunicación y Cultura. México, Número 12, Editorial Galerna.

SEGATO, Rita Laura (2006). La escritura en el cuerpo de las mujeres asesinadas en Ciudad Juárez. Territorio, soberanía, y crímenes de segundo estado. México: Universidad del Claustro de Sor Juana, Colección Voces.

- (2010). "Género y colonialidad: en busca de claves de lectura y de un vocabulario estratégico descolonial”. En QuijANO, Aníbal y Julio MejíA Navarrete (eds): La Cuestión Descolonial, Lima: Universidad Ricardo Palma-Cátedra América Latina y la Colonialidad del Poder. STOlCKe, Verena (2004). "La mujer es puro cuento: la cultura del género", Revista de estudios Feministas Artigos, Vol. 12 Núm. 2 Florianópolis, Mayo/agosto, pp. 77-105. 
SuÁrez NAVAZ, Lorena y Hernández, Rosalva (2008). Descolonizando el feminismo. Teorías y prácticas desde los márgenes. Madrid: Ediciones Cátedra Universitat de València Instituto de la Mujer.

TAussig, Michael (2012). Chamanismo, colonialismo y el hombre salvaje. Un estudio sobre el terror y la curación. Colombia: Editorial Universidad del Cauca.

VÁsQuez Del Águila, Ernesto (2000). El placer sexual masculino. Masculinidades y sexualidades en los relatos de vida de varones adultos jóvenes de clase media de Buenos Aires. Tesis de Maestría en Ciencias Sociales y Salud. Buenos Aires. Facultad Latinoamericana de Ciencias Sociales. Centro de estudios de Estado y Sociedad.

VessURI, Hebe (1970). "Brujas y estudiantes de magia en una comunidad rural”, Revista Latinoamericana de Sociología, Núm. 70/3, pp. 443-458. 